\title{
EVOCACIÓN SENSORIAL EN LA POESIA DE LA REVISTA AZUL
}

\author{
Por Dorothy Foreman Day \\ Universidad de Nebraska
}

Aun cuando casi todos los críticos están de acuerdo en que el romanticismo francés, el parnasianismo y el simbolismo tuvieron un gran impacto sobre el modernismo hispanoamericano, estos críticos no están conformes en cuanto a la naturaleza exacta, extensión y significado de su influencia. Por ejemplo, Ernesto Prado Velázquez observa en su estudio sobre la poesía de la Revista Azul: "Es verdaderamente complejo el problema de desanudar el nudo promiscuo en que se atan sin clara distinción, términos como 'decadentismo', 'simbolismo' y 'modernismo'." 1

Una gran falta de uniformidad, aunque en menor grado, también existe en relación a las características de la sinestesia, un aspecto prominente de la poesía modernista. El objetivo de este estudio es el lograr un inventario de la presencia y la naturaleza del uso de la sinestesia en la Revista Azul.

En su artículo, "In defence of synaesthesia", Alfred C. Engstrom observa:

El empleo de la sinestesia en la literatura por los escritores franceses simbolistas y decadentes, provocó un gran revuelo en el mundo de las letras del siglo xIX y dio origen a una interesante controversia sobre su valor como elemento de la expresión artística. ${ }^{2}$

La mayoría de los estudiantes del fenómeno de la sinestesia, aparentemente están de acuerdo en la definición de ella como una reacción "en la que una forma de estímulo evoca la sensación de otra, como el oír un sonido provoca la visualización de un color". 3 Quizás la más famosa caracterización de evocación sensorial anómala ocurra en la

1 Ernesto Prado Velázquez, "La poesía en la Revista $A z u l$ " (tesis profesional presentada para optar el grado de Licenciado en Letras Españolas, 1965), p. 57; tambiến citado en Ana Elena Díaz Alejo y Ernesto Prado Velázquez, Indice de la "Revista Azul". México. Universidad Nacional Autónoma de México, 1968, p. 39.

2 Alfred G. Engstrom, "In Defence of Synaesthesia", Philological Quarterly, xxv, enero, 1946, p. 1.

3 American Heritage Dictionary of the English Language, 1971. 
línea del soneto de Baudelaire, "Correspondances", que dice: Les parfums, les couleurs et les sons se répondent. ${ }^{4}$

Aunque el propósito de esta nota solamente sea el estudiar el uso de la sinestesia en la Revista $A z u l$, un breve comentario sobre la cronología y la trayectoria del modernismo en la América española podrá servir de orientación.

Algunos críticos opinan que el ensayo de Manuel Gutiérrez Nájera, "El arte y el materialismo", publicado en El Correo Germánico en 1876, debería ser considerado como el primer manifiesto de la estética modernista. " Otros críticos dan prioridad a Martí como iniciador del modernismo. 6

Los siguientes títulos nos aportan un concepto cronológico de la trayectoria del movimiento: Ismaelillo (1882) de José Martí; Cuentos frágiles (1883) de Manuel Gutiérrez Nájera; $A z u l$ (1888, 1890), Prosas profanas (1896), Los raros (1896) de Rubén Darí; La montaña del oro (1897) de Leopoldo Lugones; Perlas negras (1898) de Amado Nervo; Ritos (1898) de Guillermo Valencia; Castalia bárbara (1899) de Ricardo Jaimes Freyre; Las Pascuas del tiempo (1900) y La torre de las esfinges (1909) de Julio Herrera y Reissig; Cantas de vida y esperanza (1905) de Darío; Los crepúsculos del jardin (1905) y Lunario sentimental (1909) de Leopoldo Lugones; Alma América (1906) de José Santos Chocano.

Los escritores modernistas fueron especialmente afortunados, tomando en consideración la dificultad para publicar libros, para tener a su disposición un buen número de excelentes revistas: Venezuela: El Cojo Ilustrado (1892-1915) ; Perú: El Perú Ilustrado (1887-1897?), El Iris (1894), Prisma (1905-1907); Chile: Revista Cómica (1895-1898), Pluma y Lápiz (1900-1904) ; Argentina: Revista de América (1894), La Biblioteca (18961898), El Mercurio de América (1898-1900); Guatemala: La Locomotora (1906-1908). Pero por más excelentes que fueran estas revistas y las de otros países que no se mencionaron, ninguna es superior en calidad literaria y artística a las siguientes revistas publicadas en México: Revista Azul (1894-1896), Revista Moderna (1898-1911), El Mundo Ilustrado (1894-1914), y Arte y Letras (1904-1914).

4 Charles Baudelaire, "Correspondances", en les Fleurs du Mal, ii, 8.

5 Boyd G. Carter, "Gutiérrez Nájera y Martí como iniciadores del modernismo", Revista Iberoamericana, xxvil, julio-diciembre, 1962, pp. 295-310.

6 Ivan A. Schulman, "José Martí y Manuel Gutiérrez Nájera: Iniciadores del Modernismo (1875-1877)", Revista Iberoamericana, xxx, enero-junio, 1964, pp. 9-50. 
J. R. Spell opina de estas revistas:

Ninguna época del periodismo literario mexicano se señala con más brillo que el que se extiende desde 1894, fecha de la fundación de la Revista Azul, hasta 1911 cuando se extinguió la Revista Moderna, siendo éstas las dos mejores revistas literarias que se han dado a la luz en México. ${ }^{7}$

La Revista Azul, fundada el 6 de mayo de 1894 por Manuel Gutiérrez Nájera y Carlos Díaz Dufoo, fue el suplemento dominical de El Partido Liberal hasta la terminación de ambas publicaciones el 11 de octubre de 1896. Después de la muerte de Gutiérrez Nájera, el 3 de febrero de 1895, Díaz Dufoo se consagró a la dirección de la revista, que se dedicaba a la difusión de la literatura de importancia internacional. El Indice de la Revista Azul nos muestra que la revista modernista contenía poesía de autores que representaban a más de veinte países. ${ }^{8}$

El lector de la Revista Azul puede observar una decidida predilección editorial por la literatura francesa; en realidad los sesenta autores franceses, cuyas obras en prosa aparecen en la revista, sobrepasan en número a los mexicanos por más de seis. Manuel Gutiérrez Nájera aceptó y defendió rotundamente la orientación francesa de su publicación. Escribe: "En Francia hoy por hoy, el arte vive más intensa vida que en ningún otro pueblo, y ... es Francia la nación propagandista por excelencia." 9 Que los contemporáneos mexicanos de "El Duque de Job" reconocieron sus cualidades de dirección para revitalizar la poesía hispanoamericana, se puede ver en los siguientes extractos tomados de los poemas que aparecen en la Revista $\boldsymbol{A z u l}$ después de su muerte:

La Musa de Musset ya no la besa

En la olímpica frente soberana...

¡Murió el que dio a la lengua castellana

La exuberante inspiración francesa. ${ }^{10}$

Príncipe del arte, que en aúreos sueños gloriosos

Subiste de astro en astro, fugaz libélula errante.

7 J. R. Spell, "Mexican Literary Periodicals of the Twentieth Century", PMLA, tJV (1939), p. 835; trad. y citado por Boyd G. Carter, Historia de la literatura hispanamericana a través de sus revistas. México, Ediciones de Andrea, 1968, p. 61.

8 Dlaz Alejo y Prado Velázquez, Indice, pp. 107-110.

- Manuel Gutiérrez Nájera, "EI cruzamiento en literatura", Revista Azul, I, 9 de septiembre de I894, p. 289.

10 Juan B. Delgado, "Manuel Gutiérrez Nájera", Revista Azul, It, 17 de marzo de 1895, p. $\$ 15$. 
Sacra palpitación de los verdes campos floridos. Onda de luz vívida, rauda, armoniosa y canora Que en fecundante riego dejaste vida en un germen De florescencias $[s i c]$ regias de un virgen arte ignorado, Admiración excelsa de hispanos, galos y helenos! 11

De manera general, la primera etapa del modernismo refleja la influencia de los parnasianos franceses; mientras que la segunda etapa, cuyo punto final, con el propósito de una referencia de conveniencia, coincide con la muerte de Rubén Darío en 1916, indica una mayor percepción del simbolismo francés que del parnasianismo. Los parnasianos dan "la máxima atención a lo escultural en el verso" 12 mientras que "el simbolismo toma del parnasianismo la forma bella y breve, la forma precisa, pero no expresa una precisión objetiva, sino una imprecisión subjetiva". ${ }^{13}$ El profesor Schulman, al hablar del uso que los modernistas hicieron del color para lograr efectos estéticos, afirma lo siguiente:

Si el primer empuje hay que achacárselo al Parnaso, con su plástica sensibilidad para el color, la línea y la forma, fueron los simbolistas los que llevaron las posibilidades literarias del fenómeno cromático a un grado de perfección más altamente desarrollado y atrevido. El soneto de Baudelaire "Correspondances" (1857) fue el precursor del que Rimbaud dedicó a las vocales ("Voyelles", 1871), y del Iraité du verbe, de René Ghil (1886-1888), obras éstas que formularon la teoria de que existen relaciones entre sonidos y colores que se llaman correspondencias sinestéticas.

Estas correspondencias constituyen uno de los fundamentos más importantes del simbolismo cromático: el principio de sinestesia. ${ }^{14}$

La influencia de Baudelaire sobre los poetas que lo siguieron en el uso de la sinestesia y la correspondencia es de hacerse notar. "Desde Baudelaire -escribió Glenn O'Malley- la observación y el estudio de la sinestesia, literaria u otra, han sido muy variados y se han populari-

11 Rubén M. Campos, “A Manuel Gutiérrez Nájera", Revista Azul, w, 9 de febrero de 1896 , p. 230.

12 Francisco E. Porrata y Jorge A. Santana, edits., Antologia comentada del modernismo. Medellín, Editorial Bedout, S. A., 1974, xxxvii.

13 Juan Ramón Jiménez, El modernismo, México, Aguilar, 1962, pp. 228-229.

14 Ivan A. Schulman, Simbolo y color en la obra de Jose Marti. Madrid, Editorial Gredos, 1960, p. 444. 
zado." 15 David Zambrano escribió que el impacto de Baudelaire sobre el modernismo tuvo un lugar tardío en la trayectoria del movimiento:

Las sinestesias o transposición de sensaciones, la contribución más importante de las Flores Les Fleurs du Mal a la estética contemporánea, comienzan a aparecer más definidamente en Cantos de vida $y$ esperanza. ${ }^{16}$

Sin embargo, otro crítico le da crédito a José Martí por haber hecho uso de la sinestesia en una fecha tan temprana como 1881:

Han de pasar muchos años todavia antes de que los más audaces modernistas - Dario, Herrera y Reissig, Valencia y Lugones- hagan uso tan atrevido de la sinestesia.

... El único en español que además de él la empleaba, con cierta timidez todavía, era Gutiérrez Nájera. ${ }^{17}$

La atracción sensorial tiene muchas facetas. Un critico sugiere que:

Si la poesía armoniza o "corresponde" con el sistema nervioso, lo mismo hacen las demás artes; ... todas las artes son deleitosas no solamente debido a su atractivo auditivo o visual, sino también por las ideas que contienen. ${ }^{18}$

Otro investigador ha dividido la sinestesia literaria en dos categorías: "analogía intersensorial" o "la supuesta comparación entre las características percibidas por diferentes sentidos" y "la sinestesia clínica", que es:

Cualquier reconocimiento involuntario de una sensación, percepción o imagen de un sentido que acompaña (quizá invariablemente) al estímulo de un sentido diferente y hasta la representación mental

15 Glenn O'Malley, "Literary Synesthesia", The Journal of Aesthetics and Art Criticism, xv, junio, 1957, p. 411.

16 David Zambrano, "Presencia de Baudelaire en la poesía hispanoamericana", Cuadernos Americanos, XLix, mayo-junio, 1958, p. 220.

17 Manuel Pedro González, "En torno a la iniciación del modernismo", en Estudios criticos sobre el modernismo, edit. por Homero Castillo. Madrid, Editorial Gredos, S. A., 1968, pp. 231-232.

18 Herbert M. Schueller, "Correspondences between Music and the Sister Arts, According to 18th Century Aesthetic Theory", The Journal of Aesthetics and Art Criticism, xI, junio, 1953, p. 340. 
de ese estímulo. La sinestesia clínica incluye todo lo que se quiera decir con las descripciones de "oído iluminado". ${ }^{19}$

Los siguientes son ejemplos de "sinestesia clínica", que fueron tomados de la Revista Azul. El autor, título del poema, volumen y número de página de la revista han sido puestos después de cada una de las citas.

"fragantes joyas"

(Carlos Pio Uhrbach, "Primavera", I, 70).

"áureas melodias"

(Francisco M. de Olaguíbel, "Primavera", I, 83) .

"metálicos toques de negro y rojo"

(Jesús E. Valenzuela, "El rey negro", I, 167).

"Las brisas perfumadas"

(José Peón del Valle, "Realidad", III, 123).

"No forja la áurea rima"

(Carlos Pío Uhrbach, "Bronce florentino", 111, 25I).

"aquella nota argentada"

(Jean Richepin, "Efecto de nieve", trad. por José Juan Tablada. v, 279).

"tu risa cristalina"

(Rubén Dario, "¿Dónde estás?" IV, 51).

"Risa de plata"

(Rubén Darío, "Los centauros", Iv, 316).

"la amarga risa"

(Andrés A. Mata, "Grito bohemio", Iv, 342).

"el tropel argentino de las risas"

(Vicente Acosta, "Clemátide", Iv, 338).

"las notas cristalíneas de las risas"

(Rubén M. Campos, "A Manuel Gutiérrez Nájera", Iv, 230).

El campo está alegre, el río

lanza brillantes reflejos,

19 O'Malley, "Literary Synesthesia", p. 392. 
crujidos de argentería

de cristal, risas y besos

(Manuel Reina, "El libro de oro", II, 48).

El estímulo sensorial que proviene de una acumulación de palabras que expresan la "analogia intersensorial" ocurre frecuentemente en la poesía de la Revista Azul:

"Dame flores, perfumes y armonías"

(Manuel Gutiérrez Nájera, "Salmo de vida", I, 72).

ella es la idea que en la mente flota;

que sólo ella impresiona los sentidos;

y es luz, forma, sabor, perfume y nota

(José S. Chocano, "El fin de don Juan", v, 310).

En un mar navego

De luz y de acordes

(Enrique Fernández Granados, “Resurrexit”, II, 257).

Dad, Condes, a los cisnes cariño,

Dioses son de un país halagüeño

$Y$ hechos son de perfume, de armiño,

De luz alba, de seda, y de sueño

(Rubén Darío, "Blasón", III, 216).

$Y$ entre sedas y Iuz y fragancia

Sonrosada por casto rubor,

Va la regia señora de Francia,

Precedida de escolta de honor

(Francisco García Cisneros [François G. de Cisneros], "Tapiz Pompadour", III, 4II).

Mi senda esmalten flores,

Aromas, vida, luz

(M [anuel] Larrañaga Portugal, "Al Grijalva", Iv, 30) .

Era muy blanca, blanca y muy bella;

Era perfume, luz y harmonía

(Miguel E. Pereyra, "Intima", v, 94).

Mi pueblo dulce y bello: 
Poblado está de notas, perfumes y colores

(Manuel Reina, "La canción de mi pueblo", Iv, 61; también v, 61). (El volumen Iv de la colección consultada tiene las páginas mal numeradas: $374,57,58,59,60,61,62,63,64,383$.)

Por las rotas vidrieras

Los azules convólvulos asoman,

$\mathbf{Y}$ entran vagos rumores con el aura

$Y$ campestres aromas

(Ismael Enrique Arciniegas, "La iglesia vacía", v, 237).

Ya veis, señora, si soy discreto,

Si avaricioso guardo el secreto

De luz, de aroma, de brisa y flor

(Manuel Gutiérrez Nájera, "Del libro azul", II, 232).

Azul el cielo está, y es la montaña

Toda flores, verdor, trinos y aroma

(Luis Gonzaga Ortiz, "La boda pastoril", II, 311).

Y su amplia falda de albos satines

Frú-frús y aromas deja al pasar

(José Juan Tablada, "Abanico Luis XV", I, 245).

Y el alma soñadora del poeta,

a la caída mágica del día,

llena se siente de embriaguez secreta,

$Y$ tiene la confusa profecía

de otra existencia en más feliz planeta,

de paz, de amor, de luz y de armonía

(Numa Pompilio Llona, "La tarde", Iv, 260).

$Y$ vino el desfile de ensueños y sombras.

$Y$ fueron mujeres de rostros de estatua,

mujeres de rostros de estatuas de mármol,

tan tristes, tan dulces, tan suaves, tan pálidas!

(Rubén Darío, "La página blanca", Iv, 235).

En tanto tu beldad florece, impera,

Perfuma y rie, canta e ilumina

(Vicente Acosta, "Caléndula", v, 229). 
La evocación sensorial no siempre comunica características positivas. En los siguientes ejemplos, niega o se mengua:

"músicas invisibles"

(Jesús E. Valenzuela, "El Festín de Claudio", I, 61).

yacías trocada en polvo,

sin colores, sin esencias

(José Peón del Valle, “¡No volvió!...”, 1, 272).

Hasta el árbol tronchado en el camino,

Sin hojas y sin frutos y sin flores,

Así el anciano de experiencia y tino,

Consejos da que evitan sinsabores;

$\mathbf{Y}$ sin savia, no aromas, ni colores,

Cumple su ley y tiene su destino

(José S. Chocano, "Árboles viejos", Iv, 40).

Ya la flor sin perfume y sin colores

se hunde callada en el amante río

(Miguel E. Pereyra, "El último adiós", v, 247).

Los sueños, un tema que repetidas veces aparece en la poesía de la Revista $A z u l$, están frecuentemente relacionados con el color:

Y cual turba de pájaros cantores, los sueños, en confusa algarabía, desplegan su plumaje de colores (Laura Méndez de Cuenca, "Nieblas", II, 86).

Ha venido a posarse en $\mathrm{mi}$ alma Aureo enjambre de sacros ensueños!

(Julián del Casal, "Horridum somnium", II, 214).

Los sueños vierten polen de oro

(Balbino Dávalos, "Balada", II, 283).

"sueños de amor, doradas ilusiones"

(José I. Novelo, "Al Duque Job", II, 418).

Tú eras mi oculto tesoro, 
el ángel de mi desvelo,

la luz de mis sueños de oro

(Adalberto A. Esteva, "En la playa", Iv, 238).

"de un espejismo mágico bordan sus sueños de oro"

(José María de Heredia, "Los conquistadores", trad. por

Justo Sierra, I, 115).

"Siguen los sueños color de rosa"

(Laura Méndez de Cuenca, "Cuarto menguante", I, 218).

...enjambres de ilusiones

Color de rosa que en su seno encierra

El alma que no hirió la desventura,

(Julián del Casal, "Blanco y negro", III, 203).

Simbolizan los pétalos azules

La ilusión -astro que jamás se alcanza-

Los rosados se antojan los ensueños,

$\mathrm{Y}$ los verdes semejan la esperanza.

(María Enriqueta [Camarillo y Roa], "Hojas", III, 297).

Es el placer que cubre desnudeces

con las alas de rosa de los sueños

y apura así la dicha hasta las heces

(Felipe Valderrama, "Mi musa", v, 375).

Si en la calle, en el teatro o la iglesia

$O$ en tus sueños azules y rosas

(Clemente Palma, "El amor", I, 312).

Ah la alegre musa de las ilusiones

Que el cerebro enflora con azules sueños

(Darío Herrera, "Preludio de invierno", 1, 294).

La Revista Azul todavía contiene otros ejemplos de experiencias de] sueño:

Cuando sientas que en tus sueños cantan pájaros y flores;

A la nueva ilusión blanca de violetas coronada;

Cuando veas que al radioso despertar de la alborada

Vuelcan su urna de perfumes los ensueños y las flores; 
Piensa mucho en nuestros castos eucarísticos amores

(Rafael Martínez Rubio, "Envío", III, 284).

y su túnica viva finge radioso

sueño kaleidoscópico que raudo pasa

(Salvador Rueda, "Desfile de claveles", III, 214).

"Sueño de opio"

(Julio Florez, "Sueño de opio", Iv, 394).

Después mi arrebatada fantasía

Se pobló de magníficos ensueños

De luz y poesía

(Manuel Reina, "El sueño de una noche de verano", Iv, 181).

Los poetas cuyas obras fueron publicadas en la Revista $\mathrm{Azul}$, también utilizan la descripción sensorial para caracterizar la naturaleza general o el resultado de los logros del poeta y para exhortarlo a que continúe.

Tus versos, oh poeta, son rimas hechas de oro,

Tu genio abre las alas y marcha hacia lo azul,

$\mathrm{Y}$ en tu cerebro flotan cadencias y armonías,

Los pálidos ensueños de mágica Estambul

(Manuel Larrañaga Portugal, "El himno del gusano", II, 223).

¡Poetas y rimadores!

Sin ver el fuego extinguido

Arrojad puños de flores,

Rimas de luz y colores

¡En la Noche del Olvido!

(José Juan Tablada, "Fuegos artificiales", III, 330).

Príncipe de las cláusulas de oro,

Soberano del ritmo, te esperamos

$\mathbf{Y}$ a recibirte irán, mientras cantamos,

Tus áureos versos en alegre coro

(M[anuel] Larrañaga Portugal, "¡Oh, poeta!", Iv, 275).

Vierte el champagne su cántico sonoro,

clarín de amor que enciende los sentidos,

como versos magníficos de oro 
que en arpas de cristal fuesen tañidos

(Carlos P. Uhrbach, "Ell ensueño del champagne", Iv, 311).

Las armas armoniosas buscan tu encanto, Sonora rosa métrica que ardes y brillas, Y el pueblo ve en tu ritmo, siente en tu canto,

Sus hembras, sus claveles, sus manzanillas

(Rubén Darío, "A la seguidilla", II, 96).

Otros poemas reflejan una mayor percepción de las sutilezas que existen en el concepto del verso de los simbolistas así como de su estructura, incluyendo la sílaba como elemento básico de la comunicación poética.

Yo quisiera escribir en un idioma en que cada palabra fuera azul, cada sílaba música y aroma, y cada frase un manantial de luz. (B[onifacio] Byrne, "Mi anhelo", v, 125).

Todo es luz apacible en la estrofa, y perfume de lirio en la estancia, claridad argentina en el ritmo (José I. Novelo, "Mis musas", II, 34).

Las palabras se esculpen o se esfuman; tú les das forma, y a la vez esencia, que al pasar por tus labios se perfuman, $y$ al par que son aroma son cadencia (Francisco A. de Icaza, "Himno y lira", 11, 313).

Un músico es el campo que la armonía va casando en las hojas de miles flores, y es cada huerto alegre la sinfonfa de ópera sin sonidos fija en colores (Salvador Rueda, "El canto de las carretas", III, 247).

Voy a cantar la púrpura y el oro,

El raso, la luciente pedreria,

El pórfido, el cristal, las hermosuras,

Las rosas y la orgía

(Manuel Reina, "Noches doradas", v, 14). 
Ahi van mis versos, negras mariposas nacidas en el campo de mis sueños, no guardan ni el perfume de las rosas que libaron en días más risueños (Julián del Casal, "Ahí van mis versos", I, 345).

Da a mis estrofas las brillantes rimas, y pon frialdad de mármol en mis versos (Ismael Enrique Arciniegas, “Invocación", III, 319).

En medio de la paleta y en semicírculo puestos, alfabeto de colores están los tonos diversos. Como habla con unas notas el músico al sentimiento, y con signos el poeta al corazón y al cerebro, el pincel, lengua del mundo, deja su huella en el lienzo, y con letras de matices habla a todo el Universo (Salvador Rueda, "La paleta", 1, 342).

Los siguientes versos son un homenaje a una bella mujer:

Te amo, al saber que rubias y morenas tiénente envidia con ideal diverso, mas todas porque ven que tú encadenas Escultura, Color, Música y Verso ...

Te amo, porque las artes con terneza rinden su vasallaje a tu hermosura;

El Verso, ardor, la Música, viveza;

el Color, luz y formas, la Escultura!

(José Santos Chocano, "La bien amada", Iv, 283).

Los ejemplos citados indican que a mediados de 1890, los simbolistas estaban tomando el lugar de los parnasianos en cuanto a influencia dominante sobre los poemas publicados en la Revista $A z u l$. Un crítico que 
hizo el estudio detallado de la mencionada revista incluyendo los orígenes y significados simbólicos de $A z u l$, nos dice textualmente:

A la revista de Gutiérrez Nájera y de Díaz Dufoo corresponde la distinción de ser no sólo el primer crisol de la expresión literaria de toda Hispanoamérica, sino también el símbolo tangible de su unidad cultural. ${ }^{20}$

Si este estudio confirma la afirmación de Guillermo Díaz Plaja de que "el simbolismo es ingrediente capital del Modernismo", ${ }^{21}$ por otro lado, parece invalidar la afirmación de que "Silva fue el único poeta a quien se le pueden señalar reminiscencias de los poetas simbolistas". 22

La Revista Azul publicada a medio camino de la trayectoria de la tendencia modernista, refleja tanto el desvanecimiento de la influencia del parnasianismo, como la importación fiel del simbolismo de los escritores cuya poesía apareció publicada en la revista.

20 Boyd G. Carter, "La Revista Azul. La resurrección fallida: Revista Azul de Manuel Caballero", en Las Revistas Literarias de México, colección de discursos organizado por Antonio Acevedo Escobedo. México, Ediciones del Instituto Nacional de Bellas Artes. Departamento de Literatura, 1963, p. 73.

21 Guillermo Diaz Plaja, "El modernismo, cuestión disputada", Hispania, XLvII, scptiembre, 1965, p. 410.

22 Antonio Aita, "El significado del modernismo", Nosotros, LXXI, abril, 1933, p. 367. 